\title{
Age-dependent effects of low-dose nicotine treatment on cocaine-induced behavioral plasticity in rats
}

\author{
Susan C. McQuown • Jasmin M. Dao • \\ James D. Belluzzi • Frances M. Leslie
}

Received: 28 January 2009/Accepted: 7 August 2009/Published online: 2 September 2009

(C) The Author(s) 2009. This article is published with open access at Springerlink.com

\begin{abstract}
Rationale Epidemiological evidence of early adolescent tobacco use, prior to that of marijuana and other illicit drugs, has led to the hypothesis that nicotine is a "gateway" drug that sensitizes reward pathways to the addictive effects of other psychostimulants.

Objective To test this hypothesis, we have compared the effect of a brief, low-dose nicotine pretreatment of adolescent and adult rats on subsequent locomotor response to acute and chronic cocaine.

Materials and methods Adolescents, aged postnatal day (P) 28, and adults, aged P86, were given four daily injections of saline or nicotine $(0.06 \mathrm{mg} / \mathrm{kg}$, i.v. $)$. At P32 and $\mathrm{P} 90$, rats were given acute injections of cocaine $(0$, 0.4 or $1.0 \mathrm{mg} / \mathrm{kg}$, i.v.) and monitored for locomotor activity in either a habituated or novel test environment. To examine cocaine sensitization, rats were treated for 3 days with saline or cocaine $(0.4 \mathrm{mg} / \mathrm{kg}$, i.v. $)$, and, after 1 day of withdrawal, were given a challenge dose of cocaine $(0.4 \mathrm{mg} / \mathrm{kg}$, i.v. $)$.

Results Nicotine pretreatment did not affect acute, druginduced locomotor activity at either age. However, age differences in cocaine response were observed, with adolescent animals showing enhanced locomotor activity in the novel environment. Adolescent controls did not
\end{abstract}

\footnotetext{
S. C. McQuown $(\triangle) \cdot J$. D. Belluzzi $\cdot$ F. M. Leslie

Department of Pharmacology, School of Medicine,

University of California,

360 Med Surge II,

Irvine, CA 92697, USA

e-mail: smcquown@uci.edu

J. M. Dao $\cdot$ F. M. Leslie

Department of Anatomy and Neurobiology, School of Medicine,

University of California,

Irvine, CA 92697, USA
}

exhibit cocaine-induced locomotor sensitization, whereas adults did. Nicotine pretreatment during adolescence promoted the development and expression of a sensitized response to repeated cocaine exposure similar to that observed in saline-pretreated adult controls.

Conclusions These findings show that brief pretreatment with nicotine, in a low dose comparable to that inhaled in 2-4 cigarettes, enhances cocaine-induced behavioral plasticity in adolescent rats.

Keywords Adolescent - Locomotor sensitization . Behavioral plasticity $\cdot$ Novelty $\cdot$ Rodent

\section{Introduction}

Initiation of alcohol and tobacco use often occurs during the early teens, whereas first use of illicit substances arise later (Kandel and Logan 1984; Chen and Kandel 1995). Early use of tobacco or alcohol is associated with increased likelihood of progressing to harder drugs. Individuals who smoke cigarettes before the age of 15 are estimated to be 80 times more likely to use illegal drugs, such as cocaine, than those who do not (Lai et al. 2000). Such findings have led to the hypothesis that early teenage tobacco use may be a "gateway" to later illegal drug use (Kandel et al. 1992).

Adolescence is the final developmental period leading to adulthood, defined as 12 to 20 years in humans and postnatal days 28 to 42 in rodents (Spear 2000). Characteristic behaviors of this period such as risktaking, novelty-seeking, and increased social interactions are conserved across species (Spear 2000). During this period, there is marked neural maturation of the mesocorticolimbic dopamine system and its targets, which are 
ultimately responsible for the integration of the external environment with internal drives to produce motivated behavior (Benes et al. 2000; Chambers et al. 2003). Fiber density of amygdalocortical (Cunningham et al. 2002) and corticoaccumbens connections (Brenhouse et al. 2008) continue to increase into early adulthood. Dopaminergic innervations of the prefrontal cortex increases in density (Benes et al. 2000), and its control of prefrontal interneurons and pyramidal firing states matures during adolescence (Tseng and O'Donnell 2005). Nicotinic acetylcholine receptors are expressed on the dopamine cell bodies in the ventral tegmental area and terminals of this actively maturing circuitry (Azam et al. 2007; Wonnacott et al. 2005), and thus, nicotine exposure in adolescence may have distinct behavioral effects.

Both clinical and animal studies have shown that adolescents exhibit unique responses to addictive drugs. In animals, nicotine is more rewarding and less aversive during adolescence than at later ages (Adriani et al. 2002; Belluzzi et al. 2004; O'Dell et al. 2006). Human studies show that teenage tobacco use is more likely to produce life-long addiction and greater difficulty quitting (Breslau and Peterson 1996; Chen and Millar 1998). Animal models have clearly demonstrated that nicotine administration during adolescence causes distinct long-term neural adaptations compared to treatment in adults (Adriani et al. 2003, 2004; Abreu-Villaca et al. 2003). Together, these findings suggest that adolescents are particularly vulnerable to the addictive effects of nicotine.

Most animal studies evaluating nicotine's effects during adolescence use moderate to high doses and treatment for an extended duration. However, smokers aged 12 to 17 consume an average of 5.2 cigarettes per day (SAMHSA 2003) and progress to nicotine dependence even before daily smoking habits form (Chen and Millar 1998; Colby et al. 2000). These findings suggest that adolescents are vulnerable to persisting behavioral and neurochemical changes from even a brief, low-dose exposure to nicotine. Recent animal studies have provided significant evidence in support of this conclusion. A single pairing with nicotine can elicit a conditioned place preference in early adolescent, but not adult rats (Belluzzi et al. 2004; Brielmaier et al. 2007). We have also recently shown that brief treatment with nicotine, using an intravenous dosing procedure that simulates the effect of smoking 3-4 cigarettes per day, enhances subsequent acquisition of cocaine self-administration in adolescence, but not adulthood, thus supporting the "gateway" hypothesis (McQuown et al. 2007). Such low doses of nicotine stimulate nicotinic acetylcholine receptors which are found within reward circuitry, possibly altering development of the late-maturing mesolimbic dopamine system (Leslie et al. 2004; Wonnacott et al. 2005).
It is widely accepted that cocaine dependence results from drug-induced neural adaptations in mesocorticolimbic dopamine pathways and associated glutamatergic circuitry (Thomas et al. 2008). Locomotor sensitization, a form of behavioral plasticity induced by repeated exposure to many classes of abused drugs, has been shown in rodents to be associated with augmented drug reward and increased vulnerability to relapse (Robinson and Berridge 1993; De Vries et al. 1998). Given prior evidence that the mechanisms underlying this form of neural plasticity have not fully matured by adolescence (Laviola et al. 1995; Collins and Izenwasser 2002; Frantz et al. 2007), the aim of the present study was to determine whether adolescents might be uniquely sensitive to the effect of brief, low-dose nicotine exposure on subsequent locomotor response to acute and repeated cocaine.

\section{Methods}

Animals

Male Sprague Dawley rats were obtained from Charles River (Wilmington, MA, USA) at postnatal day (P) 17 or 74. Animals delivered at P17 arrived with dams and were housed as litters of ten male pups until weaning (P21). Young rats, after weaning, and adult rats were group housed 3-4 per cage in temperature $\left(21^{\circ} \mathrm{C}\right)$ and humidity $(50 \%)$ controlled rooms, on a 12-hour lightdark cycle (lights on at 0700 hours) with food and water available ad libitum. Twenty-eight litters provided adolescent rats with only one animal per litter used for each experimental group to minimize possible confounds due to litter effects. All tests were performed during the light part of the light-dark cycle. The animals used in this study were housed in a vivarium, accredited by The Association for Assessment and Accreditation of Laboratory Animal Care International, maintained by the University of California, Irvine (UCI) Laboratory Animal Resources personnel. All experimental procedures were performed in compliance with the National Institutes of Health $(\mathrm{NIH})$ Guide for Care and Use of Laboratory Animals (NIH No 85-23, rev. 1985), and were approved by the UCI Institutional Animal Care and Use Committee.

\section{Drugs}

The drugs used in these experiments were $(-)$ nicotine ditartrate and cocaine hydrochloride (Sigma-Aldrich, St. Louis, MO, USA) dissolved in sterile saline. Nicotine solution was $\mathrm{pH}$ adjusted to $7.0-7.4$ with $\mathrm{NaOH}$. The concentrations of nicotine are expressed as nicotine base. Propofol was obtained from Abbott Laboratories (North Chicago, IL, USA). 
Catheter implant and surgical procedure

Prior to treatment, rats were surgically prepared with a chronic catheter implanted into the right external jugular vein, as described by Belluzzi et al. (2005). Animals were anesthetized with Equithesin $(0.3 \mathrm{ml} / 100 \mathrm{~g}$, composition as described in Tagerud and Cuello 1979), and a small area on both their back and lower neck was shaved. The catheter was passed subcutaneously from the animals' back to the jugular vein where it was implanted. The cannula was flushed daily with sterile heparinized saline solution $(0.6 \mathrm{ml}$ of 1,000 units $/ \mathrm{ml}$ heparin in $30 \mathrm{ml}$ saline) to maintain catheter patency. All animals were given 3 days to recover before beginning experiments. At the end of the experiment, catheters were tested for patency with propofol, a rapid anesthetic. Data were discarded from any animal not demonstrating immediate anesthesia.

\section{Nicotine pretreatment}

The same design was used as described in McQuown et al. (2007). Two intravenous injections, spaced 1 min apart, of nicotine $(2 \times 0.03 \mathrm{mg} / \mathrm{kg} / 0.1 \mathrm{ml})$ or saline were administered daily for four consecutive days during early adolescence (P28-31) or adulthood (P86-89). Dividing the daily $0.06 \mathrm{mg} / \mathrm{kg}$ drug dose into two injections was designed to reduce both toxic effects and nicotinic receptor desensitization. The injection interval is equivalent to the standard timeout interval used in nicotine self-administration experiments (Belluzzi et al. 2005). The daily $60 \mu \mathrm{g} / \mathrm{kg}$ dose of nicotine used is comparable to the amount of nicotine inhaled in 3-4 cigarettes (Benowitz and Jacob 1990).

\section{Locomotor apparatus}

Locomotion was measured using four identical open field activity chambers $(43.2 \times 43.2 \times 30.5 \mathrm{~cm})$ connected to a common interface and computer (MED Associates Inc., St. Albans, VT, USA). Horizontal movement was recorded by 16 photo beams per side evenly spaced along each wall of two adjacent sides. Ambulatory counts equaled the number of horizontal beam breaks recorded during the test period normalized to the length of the rat in order to make unbiased comparisons between ages.

Experiment 1: Nicotine pretreatment-induced locomotion

Adolescent and adult animals were pretreated with nicotine or saline, as described above, for 3 days. On the fourth day, rats were given two intravenous injections, spaced $1 \mathrm{~min}$ apart, of nicotine $(2 \times 0.03 \mathrm{mg} / \mathrm{kg} / 0.1 \mathrm{ml})$ or saline, and were then placed in a novel locomotor chamber where activity was recorded at 5 min intervals during the subsequent 30 -min test period.
Experiment 2: Nicotine pretreatment on cocaine response

Acute cocaine-induced locomotion

Group 1-Novel environment On P32 or P90, animals were given two intravenous injections, spaced $1 \mathrm{~min}$ apart, of cocaine $(2 \times 0.2$ or $2 \times 0.5 \mathrm{mg} / \mathrm{kg} / 0.1 \mathrm{ml})$ or saline, and were then placed in a novel locomotor chamber where activity was recorded at $5 \mathrm{~min}$ intervals during the subsequent $30 \mathrm{~min}$ test period. The two intravenous injection procedure is similar to that used in earlier studies (Cao et al. 2007b; Franke et al. 2008), and is designed to model the initial phase of self-administration.

Group 2-Habituated environment This group of animals was treated similarly to group 1 except that they were habituated in the locomotor chamber $30 \mathrm{~min}$ prior to cocaine infusions.

Experiment 3: Nicotine pretreatment on cocaine sensitization

Animals were habituated to the locomotor chamber for 30 min prior to drug administration and activity was recorded (contextual conditioning). For three consecutive days beginning on $\mathrm{P} 32$ or P90, rats were given cocaine $(2 \times 0.2 \mathrm{mg} / \mathrm{kg}$, i.v. $)$ or saline as described above, and were then returned to the locomotor chamber (induction phase). After 1 day without treatment, rats were given a cocaine $(2 \times 0.2 \mathrm{mg} / \mathrm{kg}$, i.v. $)$ challenge to test for the expression of a sensitized response.

\section{Statistics}

For nicotine-induced locomotion, data were analyzed using three-way analysis of variance (ANOVA; age [adolescent, adult] $\times$ nicotine pretreatment [saline, nicotine] $\times$ nicotine challenge [saline, nicotine]). Acute cocaine-induced locomotion data were analyzed using four-way ANOVA (age [adolescent, adult] $\times$ nicotine pretreatment [saline, nicotine $] \times$ cocaine dose $[0,0.4,1 \mathrm{mg} / \mathrm{kg}] \times$ environment [novel, habituated]). For induction of locomotor sensitization, data were analyzed using four-way ANOVA (age [adolescent, adult $\times$ nicotine pretreatment [saline, nicotine] $\times$ cocaine dose $[0,0.4 \mathrm{mg} / \mathrm{kg}] \times$ days), with repeated measures on days. For expression of cocaine sensitization on challenge day, data were analyzed using three-way ANOVA (age [adolescent, adult] $\times$ nicotine pretreatment [saline, nicotine $] \times$ cocaine dose $[0,0.4 \mathrm{mg} / \mathrm{kg}])$. The habituation period prior to cocaine data was analyzed using four-way ANOVA (age [adolescent, adult] $\times$ nicotine pretreatment [saline, nicotine] $\times$ cocaine dose $[0,0.4 \mathrm{mg} / \mathrm{kg}] \times$ days $)$, with repeated measures on days. For the expression of 
contextual conditioning, data on challenge day were analyzed using three-way ANOVA (age [adolescent, adult] $\times$ nicotine pretreatment $[$ saline, nicotine] $\times$ cocaine dose $[0,0.4 \mathrm{mg} / \mathrm{kg}])$.

Significant main effects or interactions were tested separately with ANOVAs and Bonferroni's or Dunnett's corrected post-hoc comparisons. Following significant effects of day, Bonferroni-corrected $t$ tests were used for within the groups' comparison of day 3 vs. day 1. All statistical analyses were performed using SYSTAT 10 statistical software. Statistical significance was set at $p \leq 0.05$.

\section{Results}

Experiment 1: Nicotine pretreatment-induced locomotion

Three days of prior nicotine pretreatment in adolescent and adult rats did not enhance the response to nicotine challenge compared to those receiving a single injection (Fig. 1). For horizontal activity, there was a significant effect of age $[\mathrm{F}(1.66)]=31.52 ; p<0.001]$ and nicotine challenge $[\mathrm{F}(1.66)=47.77 ; p<0.001]$, but no effect of nicotine pretreatment $[\mathrm{F}(1.66)=0.88 ; p=0.35]$. Adolescents displayed significantly increased locomotion in response to nicotine challenge $[\mathrm{F}(1.35)=91.27 ; p<0.001]$, whereas adult animals did not $[\mathrm{F}(1.31)=0.30 ; p=0.59]$.

Experiment 2: Acute cocaine-induced locomotion

Cocaine-induced locomotion was measured in both habituated and nonhabituated conditions in order to examine the interaction of novelty with age and nicotine pretreatment. Whereas acute cocaine administration induced a dose-dependent increase in ambulatory activity (Fig. 2), there was no effect of nicotine pretreatment. An overall four-way ANOVA (age $\times$ pretreatment $\times$ cocaine

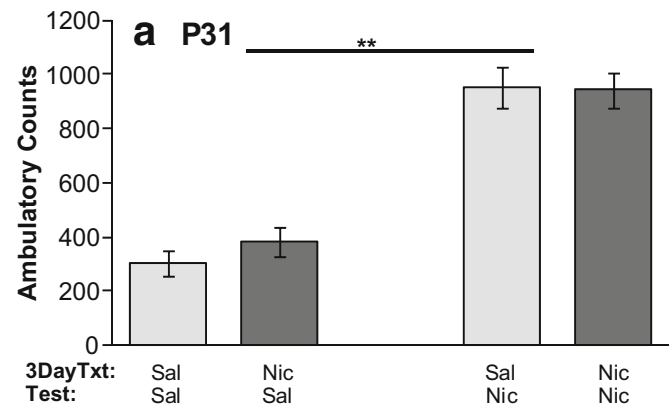

Fig. 1 Effects of age and nicotine pretreatment on nicotine-induced locomotion. Mean \pm SEM ambulatory counts are graphed for pretreated (3 DayTxt, 3 days i.v. $0.03 \mathrm{mg} / \mathrm{kg}$ nicotine or saline) adolescent $(\mathrm{P} 31$, a) and adult $(\mathrm{P} 89$, b) rats after i.v. nicotine (Nic, $0.03 \mathrm{mg} / \mathrm{kg}$ ) or saline (Sal) injection (Test). There was no effect of dose $\times$ environment) showed an effect of age $[\mathrm{F}(1.213)=$ 43.04; $p<0.0001]$, cocaine dose $[\mathrm{F}(2.213)=76.45 ; p<$ $0.0001]$, and environment $[\mathrm{F}(1.213)=283.64 ; p<0.0001]$ and an interaction between these three variables $[\mathrm{F}(2.213)=$ $8.28 ; p=0.0003]$, but no significant effect of nicotine pretreatment $[\mathrm{F}(1.213)=0.87 ; p=0.35]$. Rats receiving drug in the novel environment had greater locomotor activity at all three doses compared to those that had been previously habituated to the test apparatus $[\mathrm{F}(1.235)=127.93, p<$ 0.0001]. Age differences were seen when cocaine was given in a novel environment, with adolescents exhibiting greater activity in response to $0.4 \mathrm{mg} / \mathrm{kg}$ and $1 \mathrm{mg} / \mathrm{kg}$ cocaine doses than adults (Fig. 2).

Experiment 3: Cocaine sensitization

Consistent with earlier reports (Collins and Izenwasser 2002; Frantz et al. 2007), age differences were observed in cocaine-induced locomotor sensitization. Furthermore, nicotine pretreatment during adolescence promoted the development and expression of a sensitized response in ambulatory activity (Fig. 3), similar to that seen in adult controls.

Induction phase Since an overall four-way ANOVA (age $\times$ pretreatment $\times$ cocaine dose $\times$ days $)$ analysis showed an effect of cocaine dose $[\mathrm{F}(1.88)=32.28 ; p<0.001]$, days $[\mathrm{F}(2.176)=9.32 ; p<0.001]$, cocaine dose by day interaction $[\mathrm{F}(2.176)=4.04 ; p=0.02]$, and age $[\mathrm{F}(1.88)=11.08 ; p=$ $0.001]$, groups were divided by age. In adolescent rats, a three-way ANOVA (pretreatment $\times$ cocaine dose $\times$ day) revealed an effect of cocaine dose $[\mathrm{F}(1.45)=15.86 ; p=$ $0.0002]$ and day $[\mathrm{F}(2.90)=4.04 ; p=0.02]$, with a significant interaction between nicotine pretreatment and cocaine dose $[\mathrm{F}(1.45)=4.45 ; p=0.04]$. Nicotine-pretreated adolescents, but not saline-pretreated controls, showed a significant increase in cocaine-induced locomotion on day 3 as

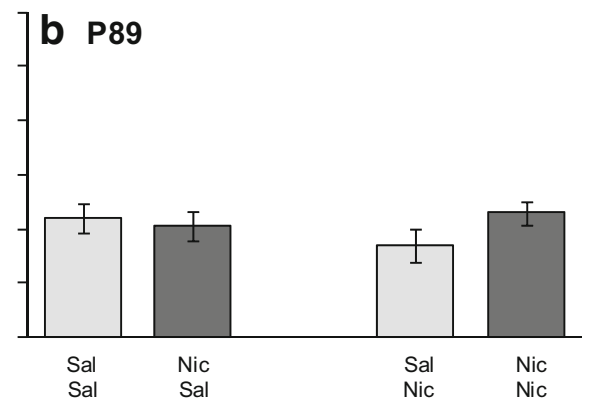

pretreatment at either age. Adolescents showed a significant nicotineinduced increase in ambulatory $\left.(\mathbf{a}) ;{ }^{* *} p<0.001\right)$ activity compared to saline-challenged controls. Adult animals did not have significant nicotine-induced locomotor behavior (b). $n=8-12$ /group 


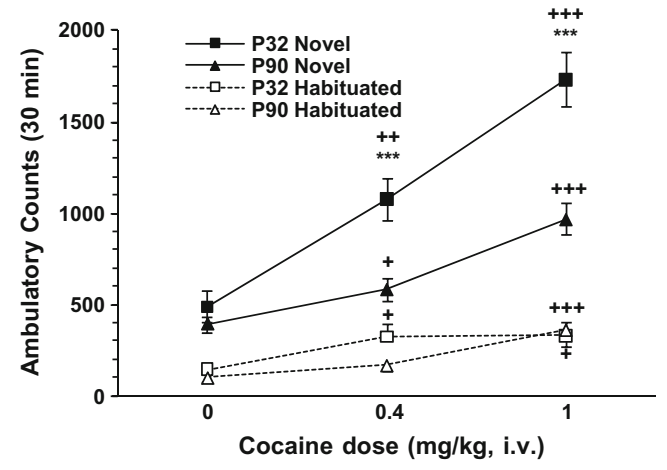

Fig. 2 Effects of age and environment on acute cocaine-induced locomotion. Mean \pm SEM ambulatory counts on day 1 for naive or habituated adolescent (P32) and adult (P90) rats after i.v. cocaine $(0,0.4$ or $1 \mathrm{mg} / \mathrm{kg})$ injections. Since there was no effect of nicotine pretreatment, groups were collapsed across this variable. Cocaine induced a dose-dependent locomotor activation in adolescent and adult rats. Novel environment (filled symbols) enhanced the behavioral response to all doses of cocaine compared to those habituated (open symbols) and reveals an effect of age. Adolescent rats show an increased response to cocaine as compared to adults in the novel environment. $+p<0.05,++p<0.01,+++p<0.001$ vs. 0 dose; ${ }^{* * *} p<$ 0.0001 vs. age; $n=11-26 /$ group

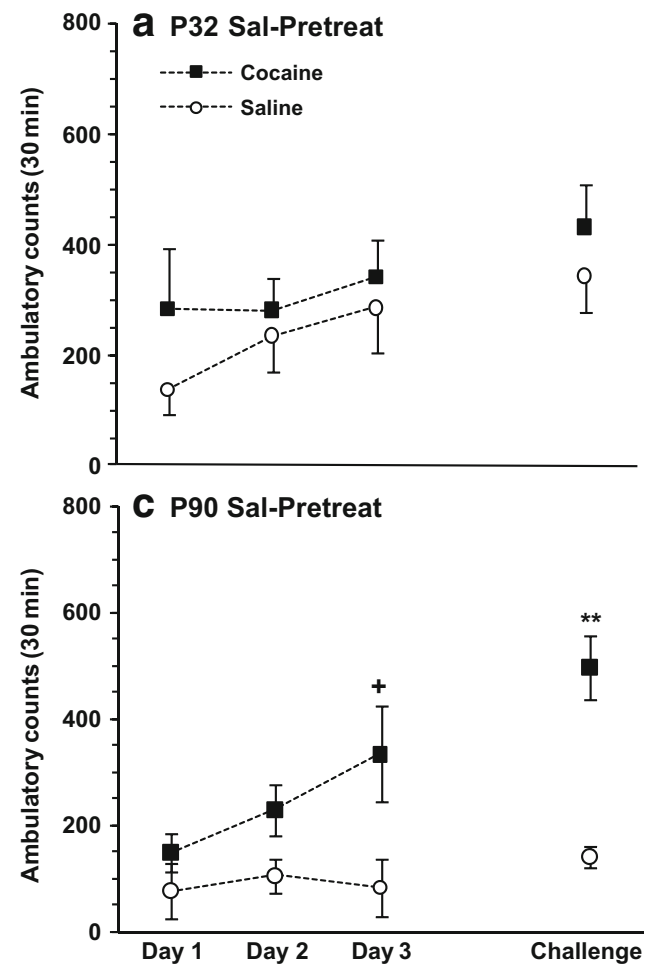

Fig. 3 Effects of age and nicotine pretreatment on cocaine-induced ambulatory sensitization. Mean \pm SEM ambulatory counts for adolescent (a, b) and adult (c, d) rats after daily i.v. cocaine $(0.4 \mathrm{mg} / \mathrm{kg})$ or saline injections for 3 days. All animals received i.v. cocaine $(0.4 \mathrm{mg} / \mathrm{kg})$ on day 5 (challenge). Nicotine pretreatment effects were significant in adolescent, but not adult rats. Panel $\mathbf{c}$ and d are shown separately for consistency, but no treatment-related significant differences were observed. Nicotine-pretreated adoles- compared to day $1(p=0.04)$; thus, nicotine pretreatment during adolescence promoted the induction of cocaine locomotor sensitization (Fig. 3b). In adults, an overall three-way ANOVA (pretreatment $\times$ cocaine dose $\times$ day) revealed an effect of cocaine dose $[\mathrm{F}(1.43)=16.56$; $p=$ $0.0002]$ and day $[\mathrm{F}(2.86)=6.81 ; p=0.002]$ and a significant interaction of cocaine dose $\times$ day $[\mathrm{F}(2.86)=5.66 ; p=0.005]$, but no significant effect of nicotine pretreatment $[\mathrm{F}(1.43)=$ $0.29 ; p=0.59]$. Although no significant effect of pretreatment was observed, data are shown separately for consistency. Saline-pretreated adults showed significant locomotor sensitization, in that cocaine-induced ambulatory activity was significantly higher on day 3 than day 1; nicotine-pretreated adults showed a strong trend towards sensitization $(p=0.059)$. There was insufficient statistical power to allow firm conclusions to be made about treatment-related statistical differences in these adult groups.

Expression On challenge day, a three-way ANOVA (age $\times$ nicotine pretreatment $\times$ cocaine dose) showed an effect of age $[\mathrm{F}(1.88)=7.63 ; p=0.007]$, cocaine dose

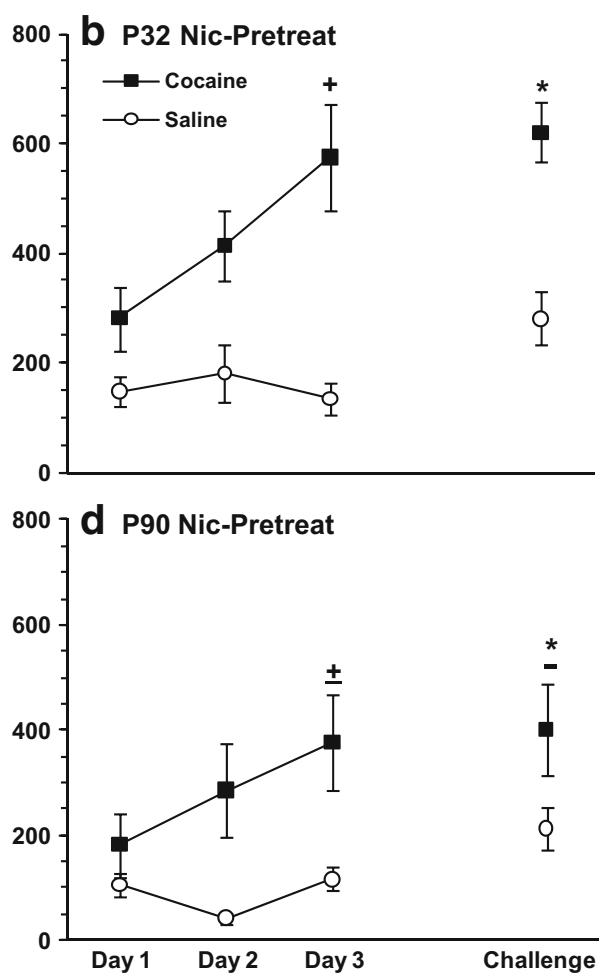

cents (b) and saline-pretreated adults (c) developed a sensitized response to cocaine on day 3 whereas nicotine-pretreated adults (d) showed a strong trend ( $\pm p=0.06,+p<0.05$, day 3 vs. day 1 ). On challenge day, expression of a sensitized response was observed in nicotine-pretreated adolescents (b) and saline-pretreated adults (c), while a strong trend was observed in nicotine-pretreated adults (d). _ $p=0.06,{ }^{*} p<0.05,{ }^{* *} p<0.01$ vs. saline; $n=11-13 /$ group 
$[\mathrm{F}(1.88)=32.31 ; p<0.0001]$, and an interaction of all three variables $[\mathrm{F}(1.88)=5.45 ; p<0.02]$. In adolescents, there was an effect of cocaine dose $[\mathrm{F}(1.45)=12.11 ; p=0.001]$ and an interaction of nicotine pretreatment and cocaine dose $[\mathrm{F}(1.45)=4.12 ; p=0.05]$. Saline-pretreated adolescent controls did not exhibit increased locomotor activity in response to the challenge dose of cocaine $(p=0.39)$, whereas nicotine-pretreated animals did $(p<0.0001)$; thus, nicotine pretreatment during adolescence promoted the expression of cocaine locomotor sensitization. In adults, a two-way ANOVA (pretreatment $\times$ cocaine dose) showed an effect of cocaine dose $[\mathrm{F}(1.43)=21.65 ; p<0.001]$, but not nicotine pretreatment $[\mathrm{F}(1.43)=0.005 ; p=0.94]$. There was a significant effect of prior cocaine exposure on cocaineinduced ambulatory activity in adult controls $(p<0.001)$, and a strong trend toward significance in nicotinepretreated adults $(p=0.06)$.

\section{Cocaine contextual conditioning}

The effect of repeated cocaine on habituation to a novel environment and contextual conditioning is shown in Fig. 4. Prior to the daily cocaine injections, animals were habituated to the chamber for $30 \mathrm{~min}$. Analysis of spontaneous activity during the habituation period over the first 3 days, using four-way ANOVA (age $\times$ pretreatment $\times$ cocaine dose $\times$ days), revealed a significant effect of age $[\mathrm{F}(1.88)=29.96 ; p<0.0001]$, day $[\mathrm{F}(2.176)=27.33 ; p<$
$0.0001]$, and an interaction of these variables $[\mathrm{F}(2.176)=$ $6.60 ; p=0.002]$, but no effect of nicotine pretreatment $[\mathrm{F}(1.88)=0.91 ; p=0.34]$. Adolescent animals had greater activity than adults on all days (day $1, \mathrm{t}(94)=6.15, p<0.001$; day $2, \mathrm{t}(94)=4.46, p<0.001$; day $3, \mathrm{t}(94)=3.91, p<0.001$; day $5, \mathrm{t}(94)=3.20, p=0.002)$, and showed habituation across days with significantly greater locomotion on day 1 than day 3 (P32 Sal, $p<0.001$; P32 Nic, $p=0.006$ ). Adult rats had less locomotor activity on the first day than adolescents and did not show any further habituation (day 1 vs. day $3, p>0.05$ ). Although age differences were apparent in the 30-min period, there were no significant differences in the level of activity during the last 5-min period immediately prior to injection (data not shown). Thus, basal differences in activity likely did not influence cocaine-induced behavior.

On challenge day, context-drug associations were determined. A three-way ANOVA (age $\times$ nicotine pretreatment $\times$ cocaine dose) showed a significant effect of age $[\mathrm{F}(1.88)=$ 9.56; $p=0.003]$ and an interaction of all three variables $[\mathrm{F}$ $(1.88)=5.30 ; p=0.02]$. Adult saline-pretreated controls exhibited contextual conditioning, as shown by a significant increase in the activity of rats that had previously received repeated cocaine in the locomotor test environment (context-drug paired) as compared to those that received saline (context-no drug paired, $p=0.01$ ). This contextual conditioning of ambulatory activity was not observed in nicotine pretreated adults, or in either adolescent treatment group $(p>0.05)$.
Fig. 4 Effects of age and nicotine pretreatment on contextual conditioning. Mean $\pm \mathrm{SEM}$ ambulatory counts during the 30 -min habituation period prior to drug treatment for nicotine- and salinepretreated adolescent $(\mathbf{a}, \mathbf{b})$ and adult (c, d) rats. Adolescent rats show a prolonged habituation, with decreased activity over days $(+p<0.05,++p<0.01$, day 3 vs. day 1$)$. On challenge day, salinepretreated adults (c) demonstrated cocaine-induced contextual conditioning. ${ }^{*} p<0.05$ vs. saline; $n=11-13 /$ group
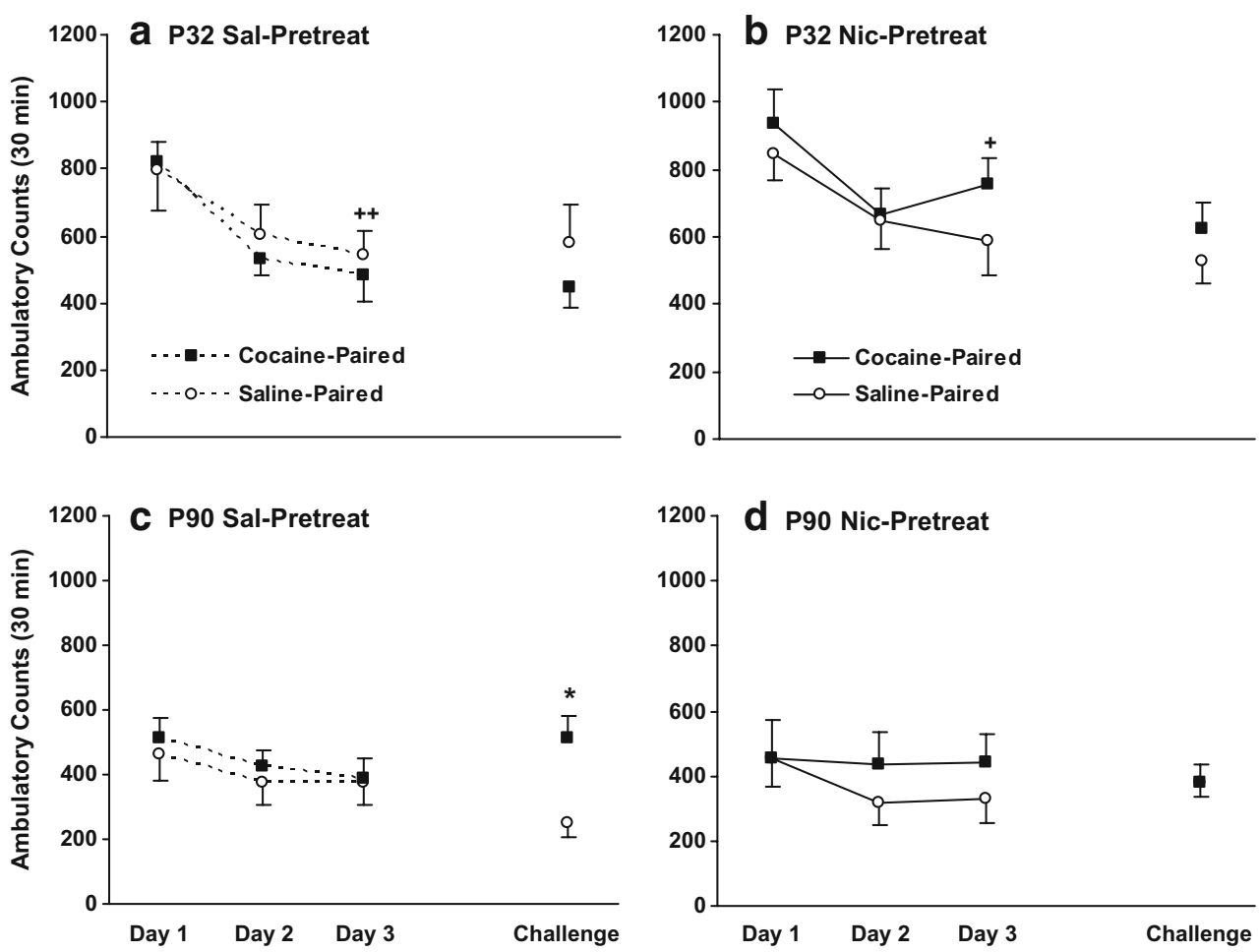


\section{Discussion}

The present study documents unique effects of nicotine on adolescent behavioral plasticity. Whereas adolescent controls did not exhibit cocaine-induced locomotor sensitization, this form of behavioral plasticity was induced by brief, four-day pretreatment with a low dose of nicotine, equivalent to that found in 3-4 cigarettes. Since cocaineinduced locomotor sensitization is a well established experimental model for drug dependence and relapse (Robinson and Berridge 2003), these findings provide further evidence for nicotine as a "gateway" drug which enhances adolescent susceptibility to other drugs of abuse (McQuown et al. 2007). Conversely, nicotine pretreatment in adulthood reduced cocaine-induced sensitization and contextual conditioning that were seen in saline-pretreated controls. Thus, nicotine has differing effects on behavioral plasticity in adolescents and adults.

\section{Nicotine sensitization}

The brief, low-dose nicotine treatment used in this model of early smoking does not result in sensitization to nicotineinduced ambulation in adolescent or adult rats. Adolescents display significantly increased locomotion in response to nicotine challenge, but not adult animals. This age difference is in accord with the literature and illustrates the sensitivity of the adolescent period to the effects of nicotine (Belluzzi et al. 2004; Cao et al. 2007a). These findings demonstrate that the four-day nicotine pretreatment regimen does not sensitize locomotor activity, although it leads to significant alterations in subsequent cocaineinduced behavioral plasticity.

\section{Acute cocaine-induced locomotion}

Nicotine pretreatment did not influence spontaneous activity or acute cocaine-induced locomotion in either age group. This finding contrasts with that of prior studies in which cross-sensitization of nicotine and cocaine-induced locomotion have been observed (Kelley and Rowan 2004; Jutkiewicz et al. 2008). However, these prior effects were seen to be dose-dependent and were observed at nicotine doses much higher than that currently used. Thus, low doses of nicotine appear to selectively influence processes relating to cocaine-induced behavioral plasticity in both adolescents and adults.

In contrast to previous studies, we found adolescents to demonstrate similar or greater response to the acute locomotor effects of cocaine compared to adults (Spear and Brick 1979; Spear and Brake 1983; Cao et al. 2007b). This may result from the extensive prior handling of the animals, which has previously been shown to result in robust cocaine responses in adolescents (Maldonado and Kirstein 2005). We did find an interaction between age and test environment, in that adolescent animals exhibited greater cocaine-induced locomotion than adults in a novel apparatus. In habituated groups, no age differences were observed. Thus, prior handling enhances adolescent response to cocaine, and novelty may synergistically increase cocaine-induced activity in adolescents above adult levels.

During induction of sensitization, we also observed increased spontaneous activity of adolescents in the novel environment, and prolonged habituation over the three test days, in contrast to the adults which had consistently low activity over the same period. These findings are consistent with earlier reports that adolescents have an enhanced sensitivity to novelty, as characterized by novelty-induced hyperlocomotion, increased time spent in a novel environment, and decreased latency to approach a novel object (Adriani et al. 1998; Douglas et al. 2003; Stansfield and Kirstein 2006).

\section{Cocaine sensitization}

In adults, repeated exposure to cocaine causes a progressive sensitization to the locomotor activating effects and incentive motivational effects of the drug (for review, Robinson and Berridge 2003). Locomotor sensitization can be separated into two components: induction and expression. Induction of sensitization is the progressive increase in locomotor activity during drug treatment, and requires both dopamine and glutamate receptor activation of the ventral tegmental area (Kalivas and Alesdatter 1993; Dunn et al. 2005). Glutamatergic input from the prefrontal cortex and amygdala are important for this phase (Wolf et al. 1995; Pierce and Kalivas 1997). Expression of sensitization is demonstrated following challenge with cocaine after a drug-free period, and is primarily attributed to neurochemical changes in the nucleus accumbens (Vanderschuren and Kalivas 2000). Such changes include increased day 1 receptor responsiveness, as well as cocaine-induced increase in dopamine and glutamate release in the nucleus accumbens core (Pierce et al. 1996; Reid and Berger 1996; $\mathrm{Li}$ et al. 1999). Both induction and expression of cocaineinduced locomotor sensitization were observed in adult animals.

In contrast, we have confirmed prior observations of a lack of sensitized locomotor response to repeated administration of a low dose of cocaine in adolescent controls (Collins and Izenwasser 2002; Frantz et al. 2007). This may result from immaturity in the dopaminergic mesocorticolimbic circuitry that is critical for mediating this response. Corticolimbic systems and their monoamine projections have not yet fully developed by adolescence (Chambers et al. 2003). In particular, the structural and neurochemical 
maturation of the prefrontal cortex and its connection with the nucleus accumbens is not complete (Benes et al. 2000; Tseng and O'Donnell 2005; Benoit-Marand and O'Donnell 2008; Brenhouse et al. 2008). Projections from the prefrontal cortex regulate activity of the nucleus accumbens and its dopaminergic afferents (Carr and Sesack 1999, 2000), and this circuitry is vital for the development of sensitization to psychostimulants (for review, Pierce and Kalivas 1997).

In nicotine-pretreated adolescents, however, both induction and expression of cocaine-induced locomotor sensitization were evident. Since nicotinic receptor stimulation has been demonstrated to regulate brain plasticity during sensitive developmental periods (Dwyer et al. 2009), repeated stimulation by nicotine may promote maturation and facilitate cocaine-induced plasticity of the mesocorticolimbic system. Nicotine has been shown to preferentially activate activity-regulated cytoskeletal-associated protein messenger RNA (mRNA), a marker of synaptic plasticity, in the prefrontal cortex of adolescents (Schochet et al. 2005). Another marker of neuronal activation, c-fos mRNA, shows adolescent-specific induction in the nucleus accumbens shell, ventral tegmental area, and basolateral amygdala after nicotine treatment (Shram et al. 2007; unpublished findings). These immature neural circuits activated by nicotine in adolescence are the same as those underlying behavioral sensitization, and connections among these regions are late to mature as discussed above. In addition, chronic nicotine during adolescence can cause greater long-term changes in dendritic morphology in the nucleus accumbens (McDonald et al. 2005, 2007) and different structural effects in the prelimbic cortex than does treatment in adulthood (Bergstrom et al. 2008). Psychostimulant locomotor sensitization is tightly associated with structural plasticity, such that increase in dendritic spine density in the nucleus accumbens core correlates with degree of cocaine-induced sensitization (Li et al. 2004). Taken together, these studies suggest that adolescent exposure to nicotine can cause unique changes in plasticity of the prefrontal cortex and nucleus accumbens which result in an adult-like sensitized response to cocaine.

\section{Contextual conditioning}

In adults, the positive effects of cocaine can quickly become associated with contextual cues in the salient environment, which gain secondary reinforcing properties (Stewart 1992). This environment-specific conditioning elicits neural activation and an increased locomotor response. Different neural circuits may underlie the unconditioned and conditioned effects of cocaine (Brown et al. 1992). Contextual conditioning requires activation of prefrontal cortex and basolateral amygdala, connections that are still maturing during adolescence (Cunningham et al. 2002, 2008). Consistent with a previous report (Schochet et al. 2004), we have found that adolescents are less sensitive than adults to contextual cues paired with a psychostimulant. Whereas adult controls demonstrated an increased locomotor response to the drug-paired environment on challenge day prior to receiving cocaine, this was not evident in adolescents. Even though they show enhanced development of locomotor sensitization in response to repeated cocaine administration, nicotinepretreated adolescents did not exhibit contextual conditioning. In contrast, nicotine pretreatment attenuated contextual conditioning in adults. These findings are consistent with the view that different neural circuits mediate the conditioned and unconditioned effects of repeated cocaine treatment in adolescents and adults (Brown et al. 1992).

\section{Clinical implications}

Our present findings further support the "gateway" hypothesis that nicotine sensitizes adolescent reward pathways to other drugs of abuse, such as cocaine. Previously, we have shown that the same brief nicotine pretreatment enhances cocaine self-administration in adolescent, but not adult rats (McQuown et al. 2007). Nicotine-treated adolescents demonstrated heightened acquisition for the task, as well as increased cocaine intake, on the first day of selfadministration testing. Our current findings provide evidence that this initial enhancement is not due to greater cocaine-induced locomotion but, rather, results from increased behavioral plasticity of the reward system.

Several epidemiological studies support the concept that brief exposure of adolescents to nicotine can have long-term consequences. A recent study showed that students who have tried a single cigarette by age 11 remain susceptible to future smoking up to 3 years later (Fidler et al. 2006). Another group found that individuals smoking only two to four cigarettes per week in adolescence were at risk of becoming addicted in early adulthood (Riggs et al. 2007). A higher proportion of early initiating marijuana smokers have reported prior cigarette smoking than those who start marijuana use after the age of 15 (Gfroerer et al. 2002). Indeed, an earlier age of onset of tobacco use predicts an increased risk to progress to illicit drugs and likelihood of becoming a heavy user (Lai et al. 2000; Kandel et al. 1992).

Thus, early nicotine exposure may increase the rate of maturation of the adolescent reward system which results greater sensitivity to cocaine-induced reward and behavioral plasticity. These findings further emphasize the importance of tobacco prevention programs directed towards adolescents and the need for additional study of neurochemical vulnerabilities during this developmental period. 
Acknowledgements The work was supported by PHS grant DA 19138 and TRDRP fellowship 16DT-0189.

Disclosure/Conflicts of interest The authors have no financial interest in the research presented in this paper.

Open Access This article is distributed under the terms of the Creative Commons Attribution Noncommercial License which permits any noncommercial use, distribution, and reproduction in any medium, provided the original author(s) and source are credited.

\section{References}

Abreu-Villaca Y, Seidler FJ, Qiao D, Tate CA, Cousins MM, Thillai I, Slotkin TA (2003) Short-term adolescent nicotine exposure has immediate and persistent effects on cholinergic systems: critical periods, patterns of exposure, dose thresholds. Neuropsychopharm 28:1935-1949

Adriani W, Chiarotti F, Laviola G (1998) Elevated novelty-seeking and peculiar d-amphetamine sensitization in periadolescent mice compared with adult mice. Behav Neurosci 112:11521166

Adriani W, Macri S, Pacifici R, Laviola G (2002) Peculiar vulnerability to nicotine oral self-administration in mice during early adolescence. Neuropsychopharm 27:212-224

Adriani W, Spijker S, Deroche-Gamonet V, Laviola G, Le Moal M, Smit AB, Piazza PV (2003) Evidence for enhanced neurobehavioral vulnerability to nicotine during periadolescence in rats. J Neurosci 23:4712-4716

Adriani W, Granstrem O, Macri S, Izykenova G, Dambinova S, Laviola G (2004) Behavioral and neurochemical vulnerability during adolescence in mice: studies with nicotine. Neuropsychopharm 29:869-878

Azam L, Chen Y, Leslie FM (2007) Developmental regulation of nicotinic acetylcholine receptors within midbrain dopamine neurons. Neuroscience 144:1347-1360

Belluzzi JD, Lee AG, Oliff HS, Leslie FM (2004) Age-dependent effects of nicotine on locomotor activity and conditioned place preference in rats. Psychopharm (Berl) 174:389-395

Belluzzi JD, Wang R, Leslie FM (2005) Acetaldehyde enhances acquisition of nicotine self-administration in adolescent rats. Neuropsychopharm 30:705-712

Benes FM, Taylor JB, Cunningham MC (2000) Convergence and plasticity of monoaminergic systems in the medial prefrontal cortex during the postnatal period: implications for the development of psychopathology. Cereb Cortex 10:1014-1027

Benoit-Marand M, O'Donnell P (2008) D2 dopamine modulation of corticoaccumbens synaptic responses changes during adolescence. Eur J NeuroSci 27:1364-1372

Benowitz NL, Jacob P 3rd (1990) Nicotine metabolism in nonsmokers. Clin Pharmacol Ther 48:473-474

Bergstrom HC, McDonald CG, French HT, Smith RF (2008) Continuous nicotine administration produces selective, agedependent structural alteration of pyramidal neurons from prelimbic cortex. Synapse 62:31-39

Brenhouse HC, Sonntag KC, Andersen SL (2008) Transient D1 dopamine receptor expression on prefrontal cortex projection neurons: relationship to enhanced motivational salience of drug cues in adolescence. J Neurosci 28:2375-2382

Breslau N, Peterson EL (1996) Smoking cessation in young adults: age at initiation of cigarette smoking and other suspected influences. Am J Public Health 86:214-220
Brielmaier JM, McDonald CG, Smith RF (2007) Immediate and longterm behavioral effects of a single nicotine injection in adolescent and adult rats. Neurotoxicol Teratol 29:74-80

Brown EE, Robertson GS, Fibiger HC (1992) Evidence for conditional neuronal activation following exposure to a cocaine-paired environment: role of forebrain limbic structures. J Neurosci 12:4112-4121

Cao J, Belluzzi JD, Loughlin SE, Keyler DE, Pentel PR, Leslie FM (2007a) Acetaldehyde, a major constituent of tobacco smoke, enhances behavioral, endocrine, and neuronal responses to nicotine in adolescent and adult rats. Neuropsychopharm 32:2025-2035

Cao J, Lotfipour S, Loughlin SE, Leslie FM (2007b) Adolescent maturation of cocaine-sensitive neural mechanisms. Neuropsychopharm 32:2279-2289

Carr DB, Sesack SR (1999) Terminals from the rat prefrontal cortex synapse on mesoaccumbens VTA neurons. Ann N Y Acad Sci 877:676-678

Carr DB, Sesack SR (2000) Projections from the rat prefrontal cortex to the ventral tegmental area: target specificity in the synaptic associations with mesoaccumbens and mesocortical neurons. J Neurosci 20:3864-3873

Chambers RA, Taylor JR, Potenza MN (2003) Developmental neurocircuitry of motivation in adolescence: a critical period of addiction vulnerability. Am J Psychiatry 160:1041-1052

Chen K, Kandel DB (1995) The natural history of drug use from adolescence to the mid-thirties in a general population sample. Am J Public Health 85:41-47

Chen J, Millar WJ (1998) Age of smoking initiation: implications for quitting. Health Rep 9:39-46

Colby SM, Tiffany ST, Shiffman S, Niaura RS (2000) Are adolescent smokers dependent on nicotine? A review of the evidence. Drug Alcohol Depend 59(Suppl 1):S83-S95

Collins SL, Izenwasser S (2002) Cocaine differentially alters behavior and neurochemistry in periadolescent versus adult rats. Brain Res Dev Brain Res 138:27-34

Cunningham MG, Bhattacharyya S, Benes FM (2002) Amygdalocortical sprouting continues into early adulthood: implications for the development of normal and abnormal function during adolescence. J Comp Neurol 453:116-130

Cunningham MG, Bhattacharyya S, Benes FM (2008) Increasing interaction of amygdalar afferents with GABAergic interneurons between birth and adulthood. Cereb Cortex 18:1529-1535

De Vries TJ, Schoffelmeer AN, Binnekade R, Mulder AH, Vanderschuren LJ (1998) Drug-induced reinstatement of heroin- and cocaine-seeking behaviour following long-term extinction is associated with expression of behavioural sensitization. Eur $\mathrm{J}$ NeuroSci 10:3565-3571

Douglas LA, Varlinskaya EI, Spear LP (2003) Novel-object place conditioning in adolescent and adult male and female rats: effects of social isolation. Physiol Behav 80:317-325

Dunn JM, Inderwies BR, Licata SC, Pierce RC (2005) Repeated administration of AMPA or a metabotropic glutamate receptor agonist into the rat ventral tegmental area augments the subsequent behavioral hyperactivity induced by cocaine. Psychopharm (Berl) 179:172-180

Dwyer JB, McQuown SC, Leslie FM (2009) The dynamic effects of nicotine on the developing brain. Pharmacol Ther 122:125-139

Fidler JA, Wardle J, Brodersen NH, Jarvis MJ, West R (2006) Vulnerability to smoking after trying a single cigarette can lie dormant for three years or more. Tob Control 15:205-209

Franke RM, Park M, Belluzzi JD, Leslie FM (2008) Prenatal nicotine exposure changes natural and drug-induced reinforcement in adolescent male rats. Eur J NeuroSci 27:2952-2961

Frantz KJ, O'Dell LE, Parsons LH (2007) Behavioral and neurochemical responses to cocaine in periadolescent and adult rats. Neuropsychopharm 32:625-637 
Gfroerer JC, Wu L-T, Penne MA (2002) Initiation of marijuana use: trends, patterns, and implications (DHHS Publication No. SMA 02-3711, Analytic Series A-17). Rockville, MD: Substance Abuse and Mental Health Services Administration, Office of Applied Studies

Jutkiewicz EM, Nicolazzo DM, Kim MN, Gnegy ME (2008) Nicotine and amphetamine acutely cross-potentiate their behavioral and neurochemical responses in female Holtzman rats. Psychopharm (Berl) 200:93-103

Kalivas PW, Alesdatter JE (1993) Involvement of N-methyl-Daspartate receptor stimulation in the ventral tegmental area and amygdala in behavioral sensitization to cocaine. J Pharmacol Exp Ther 267:486-495

Kandel DB, Logan JA (1984) Patterns of drug use from adolescence to young adulthood: I. Periods of risk for initiation, continued use, and discontinuation. Am J Public Health 74:660-666

Kandel DB, Yamaguchi K, Chen K (1992) Stages of progression in drug involvement from adolescence to adulthood: further evidence for the gateway theory. J Stud Alcohol 53:447-457

Kelley BM, Rowan JD (2004) Long-term, low-level adolescent nicotine exposure produces dose-dependent changes in cocaine sensitivity and reward in adult mice. Int J Dev Neurosci 22:339 348

Lai S, Lai H, Page JB, McCoy CB (2000) The association between cigarette smoking and drug abuse in the United States. J Addict Dis 19:11-24

Laviola G, Wood RD, Kuhn C, Francis R, Spear LP (1995) Cocaine sensitization in periadolescent and adult rats. J Pharmacol Exp Ther 275:345-357

Leslie FM, Loughlin SE, Wang R, Perez L, Lotfipour S, Belluzzi JD (2004) Adolescent development of forebrain stimulant responsiveness: insights from animal studies. Ann N Y Acad Sci 1021:148-159

Li Y, Hu X-T, Berney TG, Vartanian AJ, Stine CD, Wolf ME, White FJ (1999) Both glutamate receptor antagonists and prefrontal cortex lesions prevent induction of cocaine sensitization and associated neuroadaptations. Synapse 34:169-180

Li Y, Acerbo MJ, Robinson TE (2004) The induction of behavioural sensitization is associated with cocaine-induced structural plasticity in the core (but not shell) of the nucleus accumbens. Eur J NeuroSci 20:1647-1654

Maldonado AM, Kirstein CL (2005) Handling alters cocaine-induced activity in adolescent but not adult male rats. Physiol Behav 84:321-326

McDonald CG, Dailey VK, Bergstrom HC, Wheeler TL, Eppolito AK, Smith LN, Smith RF (2005) Periadolescent nicotine administration produces enduring changes in dendritic morphology of medium spiny neurons from nucleus accumbens. Neurosci Lett 385:163-167

McDonald CG, Eppolito AK, Brielmaier JM, Smith LN, Bergstrom HC, Lawhead MR, Smith RF (2007) Evidence for elevated nicotine-induced structural plasticity in nucleus accumbens of adolescent rats. Brain Res 1151:211-218

McQuown SC, Belluzzi JD, Leslie FM (2007) Low dose nicotine treatment during early adolescence increases subsequent cocaine reward. Neurotoxicol Teratol 29:66-73

O'Dell LE, Bruijnzeel AW, Smith RT, Parsons LH, Merves ML, Goldberger BA, Richardson HN, Koob GF, Markou A (2006) Diminished nicotine withdrawal in adolescent rats: implications for vulnerability to addiction. Psychopharm (Berl) 186:612619
Pierce RC, Kalivas PW (1997) A circuitry model of the expression of behavioral sensitization to amphetamine-like psychostimulants. Brain Res Brain Res Rev 25:192-216

Pierce RC, Bell K, Duffy P, Kalivas PW (1996) Repeated cocaine augments excitatory amino acid transmission in the nucleus accumbens only in rats having developed behavioral sensitization. J Neurosci 16:1550-1560

Reid MS, Berger SP (1996) Evidence for sensitization of cocaineinduced nucleus accumbens glutamate release. NeuroReport 7:1325-1329

Riggs NR, Chou CP, Li C, Pentz MA (2007) Adolescent to emerging adulthood smoking trajectories: when do smoking trajectories diverge, and do they predict early adulthood nicotine dependence? Nicotine Tob Res 9:1147-1154

Robinson TE, Berridge KC (1993) The neural basis of drug craving: an incentive-sensitization theory of addiction. Brain Res Brain Res Rev 18:247-291

Robinson TE, Berridge KC (2003) Addiction. Annu Rev Psychol $54: 25-53$

SAMHSA (2003) Overview of findings from the 2002 National Survey on Drug Use and Health. Office of Applied Studies, NHSDA Series H-21: Rockville, MD

Schochet TL, Kelley AE, Landry CF (2004) Differential behavioral effects of nicotine exposure in adolescent and adult rats. Psychopharm (Berl) 175:265-273

Schochet TL, Kelley AE, Landry CF (2005) Differential expression of arc mRNA and other plasticity-related genes induced by nicotine in adolescent rat forebrain. Neuroscience 135:285-297

Shram MJ, Funk D, Li Z, Lê AD (2007) Acute nicotine enhances cfos mRNA expression differentially in reward-related substrates of adolescent and adult rat brain. Neurosci Lett 418:286-291

Spear LP (2000) The adolescent brain and age-related behavioral manifestations. Neurosci Biobehav Rev 24:417-463

Spear LP, Brake SC (1983) Periadolescence: age-dependent behavior and psychopharmacological responsivity in rats. Dev Psychobiol 16:83-109

Spear LP, Brick J (1979) Cocaine-induced behavior in the developing rat. Behav Neural Biol 26:401-415

Stansfield KH, Kirstein CL (2006) Effects of novelty on behavior in the adolescent and adult rat. Dev Psychobiol 48:10-15

Stewart J (1992) Neurobiology of conditioning to drugs of abuse. Ann N Y Acad Sci 654:335-346

Tagerud SE, Cuello AC (1979) Dopamine release from the rat substantia nigra in vitro. Effect of raphe lesions and veratridine stimulation. Neuroscience 4:2021-2029

Thomas MJ, Kalivas PW, Shaham Y (2008) Neuroplasticity in the mesolimbic dopamine system and cocaine addiction. $\mathrm{Br} \mathrm{J}$ Pharmacol 154:327-342

Tseng KY, O'Donnell P (2005) Post-pubertal emergence of prefrontal cortical up states induced by D1-NMDA co-activation. Cereb Cortex 15:49-57

Vanderschuren LJ, Kalivas PW (2000) Alterations in dopaminergic and glutamatergic transmission in the induction and expression of behavioral sensitization: a critical review of preclinical studies. Psychopharm (Berl) 151:99-120

Wolf ME, Dahlin SL, Hu XT, Xue CJ, White K (1995) Effects of lesions of prefrontal cortex, amygdala, or fornix on behavioral sensitization to amphetamine: comparison with N-methyl-Daspartate antagonists. Neuroscience 69:417-439

Wonnacott S, Sidhpura N, Balfour DJ (2005) Nicotine: from molecular mechanisms to behaviour. Curr Opin Pharmacol. 5:53-59 